\title{
(Im)Pertinências de uma abordagem teórica: a neoliberalização da natureza
}

\section{(Im)Pertinences of a theoretical approach: the neoliberalization of nature}

\author{
Eve-Anne Buhler ${ }^{1}$ \\ Pierre Gautreau ${ }^{2}$ \\ Valter Lúcio Oliveira ${ }^{3}$
}

\author{
Palavras-chave \\ Mercantilização da natureza \\ Capitalismo \\ Meio ambiente \\ Governança ambiental
}

\section{Keywords}

Comodification of nature

Capitalism

Environment

Environmental governance

\begin{abstract}
Resumo
A crescente incorporação dos processos biofísicos pelo mercado verificado a partir do final dos anos 1980, em especial aqueles relacionados aos avanços das fronteiras agrícolas, foi interpretado por alguns autores em termos de "neoliberalização da natureza". Tal perspectiva foi bastante fértil nos estudos críticos das questões ambientais contemporâneas, mas foi colocada à prova ao sofrer sérias objeções desferidas a partir de diversos ângulos. Algumas dessas objeções questionam os fundamentos teóricos da tese da neoliberalização da natureza e apontam para um certo afrouxamento conceitual frente a diversidade das definições dos conceitos adotados. Outro tipo de objeção se volta para o seu limitado potencial de análise empírica, na medida em que, de tão amplo, não auxilia na compreensão de um conjunto de processos inevitavelmente incompletos e parciais. A presente contribuição propõe um balanço dos debates teóricos e empíricos sobre a neoliberalização da natureza passando por seus principais autores e tomando por referência pesquisas empíricas que temos realizado sobre o agronegócio no Brasil. Discutiremos até que ponto seus limites são devidos às inconsistências apontadas pelos seus críticos ou, ao invés (e além) disso, à falta de precauções na mobilização de uma abordagem que merece, apesar de tudo, atenção e interesse.
\end{abstract}

\begin{abstract}
The increasing incorporation of biophysical processes into the market since the late 1980 s, especially those related to agricultural frontiers, has been interpreted by some authors in terms of "neoliberalization of nature". Such a perspective has been quite fertile in critical studies of contemporary environmental issues, but it has been questionnedby suffering serious objections. Some of these objections question the theoretical foundations of the neoliberalization of nature thesis and point to a certain conceptual lack in view of the diversity of definitions of the main concepts. Another type of objection refers to its low potential for empirical analysis, since it is so broad that it does not help to understand an inevitably incomplete and partial set of processes. The present contribution proposes a balance of the theoretical and empirical debates about the neoliberalization of nature, passing by its main
\end{abstract}

1 Departamento de Geografia, Grupos de pesquisa Nuclamb e REAGRI, UFRJ. eve.buhler@igeo.ufrj.br

2 Université Paris 1 Panthéon Sorbonne, Institut de Géographie, UMR PRODIG. pierre.gautreau@univ-paris1.fr

3 Departamento de Sociologia, Universidade Federal Fluminense. valteroliveira@id.uff.br 
authors and taking as reference some empirical researches that we have carried out about agribusiness in Brazil. We will discuss about how far its limits are due to inconsistencies pointed out by its critics or, instead (and beyond), to the lack of precautions in mobilizing an hat deserves attention and interest nonetheless.

\section{INTRODUÇÃO}

Os profundos efeitos das atividades humanas sobre a natureza, cuja intensidade foi diretamente proporcional ao aprofundamento da economia capitalista, não são novidades. Paralelamente à aceleração da degradação ambiental, foram sendo criados instrumentos para tentar amenizá-la, assinalando uma tomada de consciência das sociedades acerca dos seus efeitos produzidos. Porém, a eficiência limitada das medidas tomadas para garantir a conservação dos sistemas biofísicos seria o sinal da incapacidade do capitalismo em assegurar as condições da sua própria reprodução a longo prazo. O surgimento do neoliberalismo nos anos 1980 colocou em prática uma ideologia que, além de ver no livre mercado a melhor forma de regulação das transações econômicas, estendeu progressivamente a lógica da mercantilização a diferentes esferas da vida social. O acirramento da globalização e seus desdobramentos no campo ambiental no final da década de 1990 multiplicaram as tentativas de incorporar ao mercado uma série de objetos da "natureza" tanto em termos práticos e legais - instrumentos de gestão, exploração e regulação - quanto retóricos. Chegamos, assim, a uma situação paradoxal em que a exploração da natureza pelo capitalismo neoliberal, prejudicam a sua própria reprodução a longo prazo. Paralelamente, o neoliberalismo busca amenizar os efeitos negativos que ele mesmo produziu, fomentando dispositivos de regulação ambiental que se integrem à sua lógica de acumulação. Ou seja, ao promover tais dispositivos de regulação, ele visa garantir a sua reprodução, gerando novas fontes de lucro. É a partir deste contexto que a expressão "neoliberalização da natureza" se difunde nos anos 2000 sob os auspícios de movimentos que denunciam o tratamento acentuadamente economicista da questão ambiental associado à ingerência de capitais internacionais na exploração dos recursos naturais nos países do Sul. A expressão emerge no meio acadêmico junto aos teóricos críticos, como um prolongamento das leituras feitas por pesquisadores como Neil Brenner a respeito da cidade neoliberal. Neste âmbito, os acadêmicos estão buscando analisar de forma crítica os novos contornos da relação com a natureza que o capitalismo estabelece na virada do século, como a mercantilização da biodiversidade ou do clima. Nesse sentido, três dimensões principais estão no alvo de tal abordagem: a penetração de mecanismos de mercado nos marcos da regulação ambiental; a desregulação e a alteração das funções do Estado; a mercantilização de elementos da natureza.

Contudo, essa abordagem teórica passou a ser criticada e colocada à prova a partir de objeções que questionam os fundamentos teóricos da tese da neoliberalização da natureza, e apontam para certo afrouxamento conceitual, já que ela remete a uma grande diversidade de processos nem sempre conectados entre si. O conceito de natureza pode, ainda, encontrar definições variadas conforme a perspectiva de cada autor. Outro tipo de objeção se baseia na dificuldade em ver tal abordagem funcionando nas observações empíricas, uma vez que de tão ampla e pretensiosa, acaba sendo inoperante.

A presente contribuição se propõe a fazer um balanço dos aportes e limites da abordagem da neoliberalização da natureza a partir de um debate teórico-conceitual e o recurso a ilustrações empíricas obtidas em pesquisas que temos desenvolvido desde 2011. Depois de apresentar os seus fundamentos e aportes teóricos, analisaremos as críticas que lhe são feitas tentando apontar em que medida os seus limites se devem às inconsistências defendidas por seus críticos ou, mais bem, à certas imprudências na mobilização de uma abordagem que merece, apesar de tudo, atenção e interesse. Nesse sentido, mesmo reconhecendo a importância de tais objeções e se valendo delas, defenderemos que a teoria da neoliberalização da natureza é um recurso potente na análise contemporânea da relação entre mercado, Estado e meio ambiente.

\section{QUANDO O NEOLIBERALISMO ALCANÇA A NATUREZA}

\section{Marcos teóricos e históricos}

Ao considerar que o mercado seria o mecanismo de máxima eficiência da regulação das transações humanas, opondo-se ao Estado intervencionista, o neoliberalismo busca em Adam Smith um de seus fundamentos básicos. Mas a influência dos autores clássicos do liberalismo não vai muito além. Enquanto estes 
concebiam as liberdades individuais para além da dimensão econômica, aqueles pregavam um liberalismo econômico e a implementação de um ambiente institucional e jurídico condizente com a teoria econômica neoclássica (HARVEY, 2011). Decorre de uma ideologia difundida pelos economistas da escola de Chicago nos anos 1940 e 1950, que atribui o bem-estar coletivo à generalização das trocas econômicas efetuadas num mercado livre e concorrencial (MORANGE; FOL, 2014). O neoliberalismo, nesse sentido, seria como " um ideal que expressa um projeto utópico de reorganização do capitalismo em múltiplas escalas (...) em torno da lógica e do ethos do mercado", cujas manifestações alcançam diferentes esferas da vida social (FREITAS et al., 2015, p. 240). Ele conjuga a ação e o pensamento graças a uma construção teórica sofisticada que, apesar da alegação de objetividade e de eficiência, representa interesses econômicos e sociais particulares.

Conforme Harvey, para que o neoliberalismo opere, são necessários três pilares fundamentais: direitos de propriedade consolidados; um ambiente de livre comércio; e uma organização estatal que garanta um meio institucional apropriado para tais práticas (HARVEY, 2011). Esse entendimento contraria o discurso segundo o qual o neoliberalismo coincidiria com uma retração do Estado e um encolhimento das suas atribuições. Ao contrário, conduz a redefinir o foco das intervenções estatais, produzindo o que segundo Dardot (2013, p. 17), a partir de Foucault, seria uma originalidade do neoliberalismo: a dissociação do princípio econômico do mercado da política do laissez-faire, recomendando e praticando uma intervenção governamental vigilante $\mathrm{e}$ permanente em favor do mercado, algo como um "intervencionismo de mercado". Enquanto o liberalismo atribuía ao mercado a capacidade de se autorregular, o mercado idealizado pelo neoliberalismo tem o Estado como regulador do seu funcionamento. Outra diferença com o liberalismo reside na intensidade do processo de acumulação, agora com estratégias mais intensivas de realização do lucro devido ao papel central dos agentes financeiros, e com uma maior dominância e penetração do capital, tanto na vida social quanto nos corpos individualizados. Como ideologia hegemônica do desenvolvimento capitalista (PECK; BRENNER; THEODORE, 2018), o neoliberalismo produz efeitos sobre as políticas públicas, as ações e as representações sociais, modificando profundamente a vida cotidiana dos atores sociais individuais e coletivos.

Porém, ele é raramente observado na sua forma pura e finalizada, de tal maneira que a noção de neoliberalização pode se tornar conceitualmente mais interessante em virtude do seu potencial heurístico. Esta noção está voltada para uma leitura em termos de processos que levam a esse tipo-ideal e não em observar uma determinada configuração numa abordagem sincrônica. Tal como o seu tipo-ideal, o processo de neoliberalização envolve as ações e seu controle, assim como o pensamento através do qual ele se legitima. Deve, portanto, ser entendido conjuntamente como um modo de regulação disciplinatório e como um regime de acumulação (BAKKER, 2010) que redefine os significados e os usos do espaço e dos recursos. Por fim, como projeto político, visa a assegurar as condições de reprodução e acumulação do capital e a restaurar ou reforçar o poder das elites em múltiplas escalas tendo em vista a ocorrência de um longo período social-liberal (HARVEY, 2011). Sua implementação supõe que sejam elaboradas estratégias que garantam a realização de lucro por meio da apropriação, controle, transformação e a exploração ou venda de bens cuja propriedade como recursos se consolida ao longo do processo. O conjunto destas etapas está apoiado (e conforma) num discurso que atua para a legitimação do neoliberalismo.

Nem homogênea nem unívoca, a neoliberalização configura um mosaico constituído de fenômenos diversos, mas convergentes e relativamente recorrentes. As experiências de adoção do neoliberalismo não são nem todas iguais, nem totalmente diferentes, pois são o reflexo de trajetórias locais que articulam as instituições herdadas do passado com as normas da regulação estabelecidas em cada uma das escalas. Brenner et al. (2010) apontam, neste sentido, que cada Estado assume o processo de forma singular, pressionado por regras do jogo global que transcendem as fronteiras nacionais e se impõem como tendenciais, mas que precisam adequar-se às especificidades históricas, territoriais e políticas nacionais, tendo por isso que derrogar à certos princípios do dogma. Por inscrever-se na dinâmica do capitalismo, o neoliberalismo tem como característica a sua expansão no espaço e em esferas da vida social que ainda não foram incorporadas à sua lógica, a exemplo da cultura, do corpo, ou da natureza.

A "neoliberalização da natureza" decorre de uma inserção da natureza na dinâmica do mercado, passível de ser vendida ou comprada através de mecanismos que garantam o encontro entre oferta e procura, assim como a perfeita informação e liberdade de troca. Esse fenômeno corresponde, por um lado, ao prolongamento de um processo já antigo de mobilização de 
elementos da natureza na produção de bens (mineração, agropecuária etc.), hoje num âmbito mais globalizado e liderado por tendências de mercado. Por outro lado, a neoliberalização da natureza pode corresponder também à transferência da responsabilidade da gestão e da conservação ambientais para o mercado e seus agentes. $\mathrm{O}$ mercado se tornaria, assim, o âmbito e o mecanismo regulador da conservação da natureza, substituindo as tradicionais medidas de comando e controle utilizadas pelo Estado.

Assim, os autores inscritos nesta vertente teórica têm em comum uma abordagem que busca compreender as tendências políticoeconômicas atuais que estabelecem regulações do meio ambiente a partir de mecanismos do mercado. A promoção desse processo se dá a partir da formulação de um conjunto de justificativas, apresentadas a seguir. $\mathrm{Na}$ sequência, nos dedicaremos aos argumentos mobilizados por alguns autores para compreender tais processos a partir do arcabouço teórico da neoliberalização da natureza.

Conforme seus formuladores e operadores político-econômicos, a transferência do poder de regulação ambiental para o mercado seria uma forma de conseguir uma maior mobilização dos atores econômicos e das organizações sociais. Resultaria do aumento do valor monetário dos ecossistemas ameaçados ou raros, decorrente do mecanismo básico do equilíbrio entre oferta e procura. (COSTANZA et al., 1997). Outro argumento a seu favor sustenta que a regulação pelo mercado permitiria resolver os conflitos ligados a concepções diferentes do meio ambiente, uma vez que lhe atribuiria um valor comum, sincretizado pelo preço que os agentes estão dispostos a pagar pela conservação. A regulação pelo mercado seria, por fim, uma alternativa ao modo tradicional de conservação pelo constrangimento, pois o fato de reconhecer um preço aos recursos naturais incitaria os agentes a conservá-los e valorizá-los. Conforme Martínez-Alier et al. (1998), dois artifícios se tornam primordiais para levar a cabo este projeto: a comensurabilidade e a compensação. A primeira permite comparar elementos do ambiente que não estavam avaliados conforme uma mesma unidade de medida, colocando todos eles num mesmo plano. A comensurabilidade traz, portanto, um viés reducionista, que traduz a complexidade dos ecossistemas em uma unidade de valor padronizada. A segunda corresponde à ideia de que a perda de um elemento do meio ambiente poderia ser compensada monetariamente ou por meio de uma ação de engenharia ecológica (restauração). O conceito de serviços ecossistêmicos é considerado emblemático desta mudança na forma de conceber a natureza, uma vez que explicita o fato de que são consideradas apenas as dimensões do meio ambiente úteis ao bemestar humano (regulação do clima, da água, recursos genéticos etc.). Estas servem, por sua vez, como base à avaliação do valor da natureza. Elementos da natureza são isolados e adquirem um sentido social explícito e antropocêntrico o que leva a extrai-los da complexidade dos ecossistemas. Além dos artifícios da comensurabilidade e da compensação que, conforme apontado, tornam a troca de bens naturais filosoficamente concebível e lhe dão uma tradução prática, existe uma série de manifestações que remetem a estes processos. Foi para evidenciar essas manifestações inerentes a neoliberalização da natureza que Bakker (2010) elaborou uma tipologia, na qual podem ser destacados a privatização, a mercantilização, a desregulação e re-regulação, a externalização dos custos sociais e ambientais, ou ainda, o reescalonamento da governança. A apropriação privada dos recursos comuns ou públicos constitui uma condição prévia à introdução de um bem ou serviço no mercado. Por sua vez, a reformulação do quadro regulatório visa a fomentar o mercado e facilitar a atuação dos agentes privados num âmbito concorrencial, sem arcar com os custos que sua atuação provoca (custos sanitários decorrentes da poluição ou dos impactos sociais da mudança climática por exemplo). Em consequência, os custos das chamadas "externalidades negativas" do capitalismo neoliberal são diluídos no conjunto da sociedade ou transferidos para as gerações futuras. O reescalonamento passa por um fortalecimento das organizações supranacionais que formulam os princípios, objetivos e padrões gerais da regulação ambiental a nível internacional, ao mesmo tempo em que elas incentivam a descentralização dos dispositivos e das decisões práticas para as escalas local e regional. Deste modo, a abordagem em termos de neoliberalização da natureza vê a descentralização e a gestão participativa como processos que buscam contornar a atuação do Estado para dar voz às populações diretamente envolvidas. Porém, esse processo pode levar a fortalecer estruturas de poder desiguais existentes na sociedade local e servir prioritariamente aqueles interesses que têm maior capacidade em se impor.

De forma empírica, Brannstrom (2009) identifica a tendência à neoliberalização do meio ambiente na América Latina ao considerar o surgimento dos seguintes aspectos: os baixos orçamentos alocados às instituições 
responsáveis pela questão; a adoção de mecanismos de mercado para tratar os problemas ambientais; a mercantilização dos recursos; e a descentralização da tomada de decisão para os escalões inferiores. Em meados dos anos 2000, a neoliberalização também se manifesta na responsabilização e no envolvimento dos agentes econômicos na gestão ambiental, através de medidas de incentivo. Ao despertar o interesse econômico na conservação da natureza, objetiva-se frear um conjunto de práticas de destruição dos sistemas biofísicos e promover a recuperação ambiental dos lugares nos quais estas se produzem. Os Pagamentos por Serviços Ambientais (PSA), os mecanismos de compensação ou, ainda, os selos privados que certificam as boas práticas ambientais são exemplos mais recentes desta tendência.

Apesar das possibilidades que abrem, os instrumentos da regulação ambiental inseridos na lógica da neoliberalização são bastante criticados em diferentes níveis. Em termos práticos, a sua eficiência sofre significativos limites. A lógica do envolvimento por adesão dos agentes econômicos, por exemplo, não se mostra capaz de garantir uma continuidade territorial das medidas de gestão ambiental, ainda menos conhecendo a diversidade dos instrumentos disponíveis num determinado espaço que levariam a um mosaico de práticas pouco coordenadas entre si. A RSA (Responsabilidade Social e Ambiental) ou os PSA responderiam, ainda, a uma lógica oportunista, na qual os envolvidos fariam um cálculo de custo-benefício associado à sua adesão a uma determinada medida e optariam por aquelas que pouco modificam as práticas já existentes ou que são mais baratas. Tais estratégias se mostram incapazes de provocar uma mudança profunda da gestão ambiental por parte das empresas (TONNEAU et al., 2017). Socialmente, a descentralização e a gestão participativa são apontadas como mecanismos que reforçam o papel das elites locais ou dos grupos que tem maior capital social frente aos outros agentes que padecem da falta de conhecimento e de recursos para defender suas posições no processo participativo (ELOY et al., 2013).

A implementação de práticas de RSA também mostra seus limites. Autores como Godard e Hommel (2006) apontam que as empresas têm comportamentos, no mínimo, contraditórios. Ao mesmo tempo em que aderem a medidas de RSA internamente, atuam constituindo o principal lobby em oposição às normas ambientais mais restritivas. A participação das empresas na formulação de medidas de regulação ambiental é considerada como uma forma de consolidar o papel de tais empresas na gestão ambiental, mas os estudos empíricos mostram que elas tendem, na realidade, a atuar para defender seus interesses econômicos. Evidências desse processo foram observadas por Gautreau et al. (2016) ao analisarem a participação dos agentes econômicos na definição de normas e leis que regularam a silvicultura e o agronegócio em três países sul-americanos. Eles mostram que esses agentes conseguem enfraquecer o poder regulador de tais instrumentos, ao mesmo tempo que constroem uma imagem positiva (ecoeficiente) dos setores produtivos.

Do ponto de vista teórico, há de se questionar a legitimidade dos conceitos utilizados para sustentar a mercantilização, a começar pelos artifícios da compensação e da comparabilidade, que são essenciais, por exemplo, na construção dos PSA. O pressuposto segundo o qual uma compensação global ou regional aniquilaria eficientemente os efeitos locais das degradações ambientais é bastante questionável. Por exemplo, a possibilidade aberta pelo novo Código Florestal, Lei de 2012 que dispõe sobre a proteção da vegetação nativa, de localizar a Reserva Legal obrigatória em outro Estado ou em propriedade distante da área de produção, desde que situada no mesmo bioma, levanta sérias críticas por não considerar outras escalas de funcionamento dos ecossistemas atingidos pelo desmatamento. Assim, a dinâmica de fragmentação da paisagem, o ciclo das águas ou a função das continuidades ecológicas são invisibilizados pelos mecanismos de compensação. Os mecanismos REDD+ (Redução de emissões decorrentes do desmatamento e da degradação de florestas, mais a conservação dos estoques de carbono florestal, manejo sustentável de florestas, aumento dos estoques de carbono florestal) e o mercado do carbono levantam questões similares em escala mundial.

Ao observar, finalmente, os efeitos da ideologia neoliberal manifestados no reducionismo e no utilitarismo em relação a construção social da questão ambiental, alega-se que sua tradução em dispositivos concretos de conservação conduz a uma concepção economicista e limitada da natureza. As dimensões culturais ou morais da relação sociedade-natureza se tornam periféricas, já que a mercantilização seria, pretensamente, a melhor forma de assegurar a conservação a longo prazo. A natureza passa a ser concebida através de processos isolados que respondem a uma lógica meramente utilitarista e mercantil (MARIS, 2014) e operam segundo uma perspectiva essencialista da realidade, sem levar em conta a complexidade do 
funcionamento ecossistêmico no seu conjunto. O "reducionismo" que consiste em traduzir a mudança climática em uma mera questão de gestão das emissões de gazes de efeito estufa é uma das manifestações deste processo, conduzindo a promover o que Swyngedouw (2018) qualifica de uma invocação fetichista do CO2. Para o autor, o reducionismo leva a focar apenas na síndrome patológica, reduzido a uma "coisa" objetiva e fetichizada, além de ocultar as relações de poder que permeiam a questão ambiental.

Graças à incorporação de meios (margens produtivas, áreas protegidas) e objetos (biodiversidade, carbono etc.) aos quais as estratégias neoliberais não tinham acesso até então, se criam "novas naturezas" que estão na origem dede novos mercados. A natureza fornece uma solução paliativa as contradições do capitalismo, criando oportunidades para emergência de um environnemental fix, no qual o capitalismo gera em um mesmo movimento a destruição da natureza, sua conservação e a criação de novos recursos biofísicos (CASTREE, 2008; EKERS; PRUDHAM, 2015). Como resultado do amplo alcance desta mudança na forma de pensar a conservação, a produção de conhecimentos é também impactada, sendo redirecionada para as prioridades do mercado ou para a finalidade instrumental, privilegiando novamente uma visão tecnocrática das relações sociedade-meio ambiente.

Baseado neste ponto de partida, as pesquisas que adotam o quadro teórico da neoliberalização da natureza tendem a focar nos efeitos negativos produzidos pela mercantilização desta, pela sua descentralização ou pelos sucessivos episódios de desregulação e re-regulação.

\section{UM CAMPO ANALÍTICO CONTESTADO}

Frente ao acréscimo do discurso mercantil nas grandes arenas de negociação internacional das questões ambientais, a abordagem em termos da neoliberalização da natureza suscitou um interesse crescente nas ciências sociais e humanas ao longo dos anos 2000 o que motivou a promoção de muitas pesquisas neste campo. No entanto, um debate crítico foi ganhando forma, questionando a pertinência e, portanto, a validade deste quadro interpretativo.

\section{Críticas à imprecisão do arcabouço teórico}

Uma série de críticas feitas à abordagem da neoliberalização remetem à uma certa imprecisão na forma de mobilizar os seus conceitos centrais, prejudicando a sua construção teórica. Bakker (2010) aponta, assim, a grande heterogeneidade de trabalhos sobre a neoliberalização da natureza que, por adotar quadros analíticos e objetos muito diversos não permitem a comparação ou a elaboração de um verdadeiro balanço teórico. Ela nota ainda que os próprios conceitos são utilizados de forma diferente e remetem a definições variadas. Conforme assinala, a natureza pode ser entendida ora como um bem primário, ora como um recurso, um serviço ecossistêmico ou, ainda, um arranjo sócionatural. As concepções do neoliberalismo também são distintas - e até divergentes, pois pode ser utilizado "como uma doutrina política, como um projeto econômico, como uma prática regulatória, ou como um processo de governamentalização" (BAKKER, 2010, p. 34). $\mathrm{O}$ uso do conceito de forma as vezes desencarnada, como processo geral que opera em escalas macro e não condizentes com os processos realmente analisados pode reforçar as imprecisões.

Devemos destacar, entretanto, que além dos usos pouco cautelosos, as imprecisões podem ser induzidas pelos próprios textos teóricos voltados para a construção conceitual, uma vez que conduzem a uma certa inflação semântica. Neil Brenner por exemplo, um dos principais pensadores a respeito dos espaços do neoliberalismo, considera que a sua implementação admite modalidades diversificadas ao longo do tempo e conforme os ambientes geográficos. Essas configurações particulares conferem o que ele designa como uma plasticidade forjada em função do que os economistas chamam de "path-dependency", habitualmente traduzido por dependência de trajetória (BRENNER; THEODORE, 2002). Anos depois, Brenner et al., (2010), defendem, desta vez, a ideia de uma "variegation" (variabilidade) neoliberal, definida como a produção de diferenças geo-institucionais inerentes à diversidade dos processos particulares da sua implementação em cada escala geográfica. Mais recentemente, os autores propõem a ideia de "actually existing neoliberalisms" (neoliberalismos atualmente existentes), para evitar designações essencialistas e reforçar que o neoliberalismo reveste formas apenas conjunturais (PECK; BRENNER; THEODORE, 2018). Outros autores buscaram pensar o neoliberalismo na sua diversidade, sugerindo a ocorrência de variedades de neoliberalismos na sequência das discussões acerca da variedade de capitalismos. 
Bakker (2010) salienta assim um neoliberalismo híbrido, enquanto Freitas et al. (2015) preferem a perífrase not-quite-neoliberal natures (naturezas não exatamente neoliberais), se referindo aos países latino-americanos dos anos 2000 , principalmente aqueles que conheceram a "onda rosa". O not-quite-neoliberal natures expressa um retorno do Estado intervencionista na economia e na gestão do território sem, no entanto, que estes países tenham rompido com o modo neoliberal de gestão dos recursos e do meio-ambiente. Indica que, na prática, coexistiriam uma regulação da natureza pós e neoliberal se aplicando de forma diferenciada conforme os objetos das ações, as pressões e os interesses em jogo. Pós-neoliberalismo e socialneoliberalismo também são noções utilizadas por outros autores que remetem a contextos similares.

A diversidade dos neoliberalismos constitui, desta forma, um limite teórico, pois não consegue estabelecer minimamente uma tipologia, ou um ranqueamento dos processos que lhe são próprios. A sua extrema variabilidade conduziria à dissolução do conceito em uma multidão de variações conforme a diversidade das situações às quais ele se aplica, tendo sempre alguma pertinência, mesmo que apenas parcial. Identificamos, por um lado, uma série de aportes que, por tomar uma atitude cautelosa, acabam diluindo a neoliberalização em uma multidão de variações que a afastam de um entendimento minimamente comum do conceito. Por outro lado, encontramos autores que fazem uma aplicação mecânica da neoliberalização a inúmeros estudos de caso sem reflexividade, e que a aplicam como um dado, um fenômeno reificado e essencializado. Em ambos os casos, o conceito perde seu potencial heurístico e se torna pouco apropriado para entender os processos em curso.

\section{Limites decorrentes da sua operacionalização}

Outra série de críticas versa sobre a realidade empírica associada às tentativas de implementação de mercados ambientais, e em particular dos pagamentos por serviços ambientais. No âmbito brasileiro, as publicações que procuram avaliar o caráter neoliberal da implementação de PSA conduzem a uma apreciação cética sobre a sua real natureza. Tudo indica que a tradução dos princípios que sustentam um mercado dos serviços ambientais em instrumentos concretamente implementados leva a sua adulteração, os transformando em programas convencionais de subsídio ou em programas sociais de redistribuição de renda.

Um primeiro exemplo se encontra nos financiamentos liberados para a agricultura no âmbito do plano ABC (O Plano Agricultura de Baixa Emissão de Carbono). Este Plano visa a redução das emissões de carbono na agricultura graças a adesão voluntária dos produtores a medidas de mitigação remuneradas, tendo os grandes produtores como destinatários prioritários. Rosa (2017) mostra que estes financiamentos correspondem, nos fatos, a uma oferta de crédito subsidiado para grandes produtores que não conseguiram acesso a outros programas públicos de financiamento. No Estado de Minas Gerais, os instrumentos implementados são desviados da sua finalidade por ser destinados a produtores que ignoram o seu objetivo real e cujas práticas já contemplavam os objetivos perseguidos pelo plano.

Outro caso emblemático é analisado por Aubertin et al. (2014) ao estudar a implementação do PSA na Amazônia para lutar contra a mudança climática e capturar carbono. Para os autores, o Brasil aproveitou estes programas como forma de reforçar a sua soberania sobre a gestão da floresta frente às pressões internacionais (graças ao Fundo Amazônia, que tem gestão nacional, mas que permite acessar verba internacional) e usou os PSA como forma de disfarçar políticas redistributivas e inclusivas voltadas para as populações indígenas, de pequenos agricultores e de comunidades tradicionais. Uma análise detalhada dos instrumentos implementados, dos seus objetivos e do objeto que motiva o pagamento mostra que eles são, na prática, parecidos com os tradicionais subsídios, financiando, neste caso, a transição ecológica, a restauração florestal ou o desmatamento evitado. O pagamento se destina, de fato, a financiar a mudança de práticas, e não à compra de um hipotético serviço. Desta forma, o valor do PSA se estabelece em função do custo de oportunidade em adotar uma determinada prática e acessar um recurso disponível, ao invés de ser construída como remuneração de um serviço. Vale considerar, além disso, que o mercado, mesmo que existisse, tem o poder público como único "cliente". Para Aubertin et al (2016), a referência aos PSA é qualificada de retórica estratégica, já que responde mais a uma estratégia para captar verba no âmbito internacional do que uma preocupação real com a implementação de um mercado ambiental.

Em outro artigo, Aubertin et al. (2016) confrontam o projeto de neoliberalização da natureza embutido na formulação dos PSA com o pragmatismo da realidade. Os autores 
concluem que não se consegue criar um mercado dos serviços ecossistêmicos simplesmente porque eles não geram suficiente lucratividade: os elementos da natureza que interessam aos agentes do capitalismo, são aqueles passíveis de serem convertidos em recursos e dos quais possam extrair uma taxa de lucro atrativa (petróleo, aço, soja, etc.). Nem as características do mercado, nem a abordagem instrumental da natureza pela sociedade capitalista permitiriam a realização de tal objetivo. Por esse mesmo motivo, as transações são efetivamente assumidas por agentes que não têm o lucro como principal objetivo ao realizar a transação. Numa perspectiva próxima, Foyer et al. (2017) se referem a uma "economia da promessa" para designar o paradoxo entre a promessa do PSA na sua formulação teórica versus sua implementação:

se algumas formas de neoliberalização hegemónica são observadas em certas escalas (fóruns internacionais entre outros), não são sinônimos de mercantilização na sua implementação [...] e se bioprospecção ou REDD+ remetem bem a certa forma de governança neoliberal, essa governança tem uma dimensão amplamente virtual. (FOYER et al., 2017, p. 245)

Porém, Aubertin et al. (2016), não chegam a concluir que os PSA constituem apenas uma mudança de legitimação aplicada a antigos instrumentos. Este mecanismo leva a governanças hibridas, por incluírem uma maior diversidade de agentes quando comparado ao modelo clássico do comando e controle.

Os limites enfrentados na operacionalização do projeto político da neoliberalização da natureza não devem ocultar, mesmo assim, o efeito performativo do discurso produzido, uma vez que motivou novos tipos de políticas públicas, assim como a criação de instrumentos inéditos com objetivos reformulados em relação às políticas públicas de comando e controle. Apesar de não funcionar conforme o esperado, acabam alterando as formulações da questão ambiental e, certamente, a percepção da natureza pelos agentes envolvidos, em todos os escalões.

\section{Restituir um potencial analitico ao conceito}

Estimamos que as críticas formuladas contra a abordagem da "neoliberalização da natureza" não chegam a invalidar sua pertinência para descrever certas dimensões dos processos contemporâneos de incorporação do mundo biofísico ao capitalismo, à condição de se tomar algumas precauções analíticas.

\section{Algumas precauções metodológicas e analiticas}

Uma primeira precaução a se tomar consiste em dar um sentido mais rigoroso à termos amplamente utilizados no campo da ação política e da militância que, no campo científico, precisam ser claramente conceituados. Uma das características da crítica social ao neoliberalismo durante os anos 2000-2010 foi ter atribuído um sentido anti neoliberal a formas de gestão da natureza impulsionadas ao longo do decénio neoliberal, realizando, de tal forma, um anacronismo patente. Por exemplo, as unidades de conservação são amplamente apresentadas como instrumentos que permitem frear o avanço das fronteiras agrícolas "neoliberais" na América Latina. Da mesma forma, o multiculturalismo, inscrito num grande número de constituições latino-americanas durante os anos 1980-1990, é apresentado como um meio de resistência ao neoliberalismo. Essa ressignificação atual esquece, porém, que a difusão das UCs no continente foi implementada por agentes neoliberais dos anos 1990: as ONG do setor internacional da conservação (DUMOULIN KERVRAN; RODARY, 2005) ou, ainda, o Banco Mundial que condicionava a ajuda ao desenvolvimento à criação de UC. As UC estão, dessa forma, intimamente associadas ao período de extrema dependência econômica dos países latino-americanos às instâncias financeiras internacionais e às políticas de ajuste estrutural (DUMOULIN KERVRAN, 2006). Apesar de parte das UCs criadas durante esse período constituírem, de fato, um limite ao avanço agrícola, no Brasil em particular, grande parte destas foram localizadas em áreas pouco ameaçadas naquele momento. Um processo similar se produziu com o multiculturalismo. Este processo é pensado hoje - e com razão como o resultado de lutas seculares em favor do reconhecimento do direito das populações précolombianas e de origem africana. Contudo, a influência dos agentes internacionais foi, novamente, um fator decisivo da sua inscrição na lei. Com o surgimento do paradigma da "conservação integrada", segundo o qual precisa fomentar a participação das populações locais na conservação da natureza (RODARY, 2003) esses agentes incentivaram o reconhecimento dos territórios autóctones para permitir a essas populações obter lucros monetários pelo seu envolvimento na conservação. Desta maneira, o 
multiculturalismo é, também, uma co-invenção do neoliberalismo que permite integrar ao mercado espaços e populações até então excluídas (GROS et al., 2011).

Uma segunda precaução consiste em evitar essencializar formas de gestão da natureza como sendo neoliberais, inclusive quando estas parecem favorecer claramente um processo de neoliberalização. Uma das técnicas essenciais para introduzir a natureza no mercado consiste em "traduzi-la" na forma de informação e, concretamente, de bases de dados. Castree (2003) identifica cinco processos chave na sua mercantilização: a privatização, a alienabilidade, a individuação, a abstração e a valoração. Em cada uma desta três fases, a implementação de dispositivos informacionais é necessária para permitir a codificação dos bens a serem trocados, seu status jurídico e a sua valoração. A cada um destes estágios a implementação de dispositivos informacionais se faz necessária para sustentar sua circulação. Pode-se dizer que a informação permite desenraizar (disembedding) a natureza do seu contexto geográfico o que permite integrá-la aos fluxos globais:

With the ability to abstract and disembed environment from its sensory experiences and local contextualities and include it in symbolic tokens based on information, it can be transferred through time and space and is thus included in the space of flows (BUTTEL, 2006).

A cartografia de certas dimensões particulares do vivente, enquanto dispositivo que permite abstrair do real os elementos que interessam ao capital, poderia corresponder a essa situação: cartografia da biodiversidade, dos serviços ecossistêmicos, da captação de carbono, todas contribuindo para desenraizar a natureza do conjunto complexo ao qual ela pertence. Ao permitir a formalização de entidades abstratas (um serviço ecossistêmico por exemplo), permitem compará-los em diversas escalas sem precisar percorrer fisicamente o espaço para conhecê-lo e, portanto, criar um ambiente de troca com base monetária (mercado do carbono florestal, por exemplo). Percebemos, portanto, como os dispositivos informacionais podem participar, pelo menos na teoria, do processo de comensurabilidade dos valores operados pela "linguagem económica" de valorização, conforme os termos de Martínez Alier (2004). Consequentemente, pode-se avaliar que os dispositivos informacionais das instituições ambientais contribuem para um processo de reformulação cultural neoliberal quando implementados, veiculando uma visão simplista e fragmentada de um ambiente infinitamente mais complexo.

Contudo a informação, particularmente quando numérica, não deve ser entendida apenas como uma técnica essencialmente neoliberal. A construção de bases de dados sobre o ser humano e a natureza começou com a emergência do Estado moderno e a sua vontade de controlar e lidar com (to take in charge) a realidade social e biofísica (SCOTT, 1998). A criação dos cadastros cartográficos entre os séculos XVII e XIX ilustra essa mudança. Na época, os objetivos do Estado são principalmente o controle social, fiscal, assim como o melhoramento da produção agrícola. A informação cadastral assumiu também um papel importante na democratização das sociedades ocidentais, por introduzir uma concepção mais igualitária do imposto, fundado sobre um cálculo mais objetivo da riqueza. Hoje, a informação é, em certas circunstâncias, um fator essencial do acréscimo da justiça ambiental pois permite uma melhor distribuição do risco. Os movimentos sociais, em particular, a concebem como uma ferramenta da resistência ao neoliberalismo quando ela permite tornar visível o avanço do extrativismo e, portanto, sua denúncia, a exemplo dos sites militantes de cartografia e de análise dos conflitos ambientais tais como o Observatorio Latinoamericano de Conflictos Ambientales (Olca.cl); o Observatorio de Conflictos Mineros de América Latina (Ocmal.org); Mapa de Conflitos envolvendo Injustiças Ambientais e de Saúde do Brasil (http://mapadeconflitos.ensp.fiocruz.br/).

Uma terceira precaução pode consistir em analisar eventos particulares nos quais podem ser observados com muitos detalhes as formas de hibridação entre as lógicas neoliberais e outras lógicas. A sociologia ambiental, por exemplo, atribui uma importância particular aos conflitos. De um ponto de vista metodológico, esse interesse está ligado ao fato de que nessas situações, os agentes presentes argumentam fortemente a respeito das suas posições. Os pesquisadores têm acesso a discursos importantes que permitem entender a complexidade das "linguagens de valorização" , ou sistemas de valores, que se opõem. Em contraste com as duas situações anteriores, que valorizavam a contextualização do processo no longo prazo, se trata aqui de detectar curtos períodos durante os quais importantes decisões são tomadas. O estudo da construção dos sistemas contemporâneos de gestão da biodiversidade constitui, por exemplo, uma oportunidade para a compreensão da neoliberalização da natureza. A propósito dos 
programas mexicanos de pagamento por serviços ecossistêmicos, McAfee e Shapiro (2010) mostraram que estes foram objeto de controversas que opunham visões diferentes do papel das populações camponesas em relação à biodiversidade. Estas posições remetiam a divergências em relação aos objetivos de mercantilização do vivente. Aqueles que concebiam os camponeses como uma ameaça para a biodiversidade defendiam o pagamento por serviços ecossistêmicos como forma de incentivar o abandono das suas práticas agrícolas (afastá-los da floresta). Ao contrário, aqueles que concebiam estes mesmos camponeses como os agentes que tinham coconstruído a biodiversidade florestal durante séculos, viam nos pagamentos por serviços ecossistêmicos uma maneira de apoiar a permanência das suas práticas tradicionais. Neste trabalho, McAfee e Shapiro (ibid.) mostraram como duas posições sobre a relação homem-natureza radicalmente opostas de um ponto de vista filosófico, podiam convergir para uma mesma confiança no papel do mercado para atingir os objetivos de conservação.

Atualmente, a maioria dos países da América latina adaptam seus aparatos jurídicos e seus instrumentos de monitoramento das mudanças ambientais para contribuir com a conservação da biodiversidade e para a luta contra a mudança climática (GAUTREAU et al., 2016). Os debates geridos por estes "eventos" oferecem uma ocasião de acompanhar nos detalhes o processo de neoliberalização. Por exemplo, a América latina e o Caribe adotaram recentemente um "Acordo Regional sobre o Acesso a Informação, Participação Pública e Acesso à Justiça em Assuntos Ambientais na América Latina e no Caribe" (2018). O acordo representa, aparentemente, uma vitória para os movimentos sociais pois se torna uma ferramenta para fortalecer o controle cidadão sobre a degradação ambiental. Porém, em realidade, o acordo foi igualmente defendido por parte do meio empresarial, que vê nele uma forma de derrubar barreiras invisíveis ao livre mercado: as diferenças de acesso à informação, por exemplo, são vistas como assimetrias injustas que prejudicam livre concorrência e a informação pura e perfeita (GAUTREAU; MONEBHURRUN, 2017).

\section{Um recurso útil para analisar o sentido do "neo"}

O uso imoderado da categoria "neoliberalização" para descrever qualquer processo de uso mercantil da natureza prejudica, a nosso ver, a sua força heurística. É necessário, portanto, voltar a dar "valor" científico à noção para reforçar o seu poder explicativo acerca dos processos recentes que tem no mercado seu principal mediador da relação sociedadenatureza. A título de exemplo, podemos considerar a noção de "fronteiras neoliberais" aplicada aos novos territórios do agronegócio dos anos 2000 na América do Sul (BRANNSTROM, 2009), um tanto "ineficaz". De fato, ele descreve, a princípio, processos clássicos de expansão da agricultura moderna em detrimento de áreas cobertas com vegetação e utilizadas por populações rurais ou indígenas, significando dizer que não nos parece auxiliar na compreensão de novos fenômenos ou dimensões que possam distinguir a realidade atual daquelas do passado. O fato de esta agricultura moderna ser, em parte, levada por agentes globalizados também não atesta o caráter neoliberal do processo. Desde o século XVI, a incorporação crescente do meio natural à esfera mercantil ocidental parece prosseguir conforme modalidades muito similares.

A nosso ver, seria mais precisamente nas formas de acompanhamento destes processos conduzidos e delimitados pelo Estado que se poderia ler a dimensão realmente neoliberal do processo. A título de exemplo, o Estado brasileiro desenvolve desde 2012 (com o novo Código Florestal) um instrumento de regulação agroambiental chamado Cadastro Ambiental Rural (CAR), que permite conhecer a situação ambiental de cada estabelecimento e verificar se respeita ou não a legislação neste tema. Tratase, aparentemente, de um instrumento que visa a frear o desmatamento e a ordenar a exploração do território de forma racional. A observação empírica dos seus efeitos, porém, é outra, já que ele se traduz também em um instrumento de informação que permite aos investidores, inclusive estrangeiros, "ler" o território. Nos cerrados em particular, marcados por aquisições ilegais de terras, a indeterminação fundiária constitui um freio à entrada de capitais estrangeiros preocupados com a segurança jurídica. A implementação do CAR se torna uma ocasião para o Estado confirmar uma anistia geral sobre o desmatamento ilegal anterior a 2008, mas também de "lavar" as áreas que foram adquiridas ilegalmente. Os produtores que se beneficiam de apoios políticos e jurídicos necessários conseguem, pela inscrição do seu CAR, reforçar a legitimidade de seus títulos de propriedade (BÜHLER; OLIVEIRA, 2018). Este instrumento é, dessa forma, neoliberal no sentido de Bakker (2010) já que institui uma forma de "disciplinamento" das normas antigas - no caso, arranjos locais para aceder maciçamente e ilegalmente ao fundiário - por 
fazer emergir novas formas, mais adequadas às exigências do mercado agrícola internacional e legíveis à distância por esse mercado. $\mathrm{O}$ discurso de Izabella Teixeira (Ministra do Meio Ambiente responsável pela finalização da reforma do Código Florestal) ao tomar posse na Academia Nacional de Agricultura em 2015 explicita essa visão:

\section{"A tecnologia serve para o bem, não apenas para fiscalizar, mas, para isso, a gente precisa ter um discurso político institucional muito bem construido, em que o setor privado enxergue condições de competitividade e não de burocracia $e$ barreiras [...]". E acrescenta: "Temos que ter transparência nos resultados, nos basear nos resultados e não nos problemas, fazer um reequilíbrio nessa equação". (SNA, 2015).}

Durante as pesquisas empíricas que realizamos em áreas de fronteira agrícola, verificamos um engajamento muito claro dos mais importantes empresários agrícolas e dos seus sindicatos a favor do CAR, sob a justificativa de que se tratava de um instrumento que reforçava a regulação, lhes conferindo benefícios para capitalizarem-se, ao mesmo tempo em que ajudava a apagar o caráter muitas vezes ilícito da origem dos seus títulos fundiários quando não houvesse a constatação de sobreposição de áreas reivindicadas por diferentes "proprietários". Neste processo, o caráter informacional do CAR é central: a base de dados que ele constitui é formada dos limites das propriedades agrícolas, assim como da superfície da vegetação colocada em reserva pelos proprietários. Estamos, desta forma, frente a um novo processo, no qual a informação sobre o estado do meio ambiente numa determinada propriedade pode contribuir para forjar o seu valor fundiário, na medida em que quanto mais estiver em conformidade com a lei, maior o seu valor para um investidor em busca de garantias jurídicas para o seu investimento. $\mathrm{O}$ fato de tornar a natureza legível para atender aos interesses do mercado e contando, ao mesmo tempo, com a proteção e o acompanhamento do Estado (que gere o sistema de informação) faz com que tais fronteiras possam ser conceitualmente analisadas como "fronteiras neoliberais".

Observa-se, a partir deste exemplo, que a organização do processo produtivo e a relação entre Sociedade - Estado - Mercado promovidos a partir de forte influência dos atores do "agronegócio" remetem a um processo de reagenciamento das regulações estatais do meio ambiente que questionam e reorientam os padrões da regulação pública (OLIVEIRA; BÜHLER, 2016). As estratégias dos atores implicam atuar junto ao poder público seja, por um lado, no sentido de garantir uma liberdade de ação contra regulações de determinados tipos ou preferindo a desregulação (leis ambientais e trabalhistas são sempre questionadas) ou, por outro lado, para pressionar politicamente de forma a gerar re-regulações que beneficiem um processo de privatização de recursos naturais. Castree (2008) descreve esse processo como a dotação de direitos de propriedade sobre fenómenos ambientais ou sociais que anteriormente eram controlados pelo Estado ou pela comunidade, ou que ainda não eram controlados por ninguém. Notamos em contextos empíricos distintos uma atuação do Estado na facilitação ou promoção destes processos de privatização. A revisão do código florestal finalizada em 2012, as reformulações de leis ambientais e fundiárias promovidas nos estados da federação vão neste sentido. Em ambos os casos o Estado promoveu o laissez-faire e fez vista grossa, quando não agiu deliberadamente para atender as necessidades dos atores do agronegócio, seja para permitir o avanço das fronteiras agrícolas, seja fomentando a grilagem de terras e a inclusão destas no mercado fundiário. Uma vez gerado o fato, a re-regulação serviu para perdoar multas e punições e para garantir segurança jurídica para investidores de maior envergadura. Como já salientado, a intervenção do Estado é bastante significativa, mesmo (ou, sobretudo) quando deixa de intervir.

\section{CONSIDERAÇÕES FINAIS}

Em síntese, defendemos a pertinência e o potencial heurístico das abordagens em termos de neoliberalização da natureza, desde que sejam tomadas algumas precauções no seu uso, começando por um esforço de definição e de explicitação dos conceitos. Os limites apontados no segundo tópico não invalidam a abordagem no seu conjunto e apontam mais para a necessidade de estar vigilante para evitar qualquer uso normativo, anacrónico ou engessado numa perspectiva essencialista.

Desde que sejam tomadas algumas precauções, a abordagem da neoliberalização da natureza pode ser útil para pensar as mutações do mundo biofísico, tanto do ponto de vista material quanto das suas representações. A mercantilização da natureza, por exemplo, pressupõe um conjunto de processos que permitirão delimitar unidades discretas (uma 
paisagem, um serviço ecossistêmico, uma tonelada de $\mathrm{CO}_{2} \ldots$ ) e lhes atribuir um valor monetário. A neoliberalização leva, portanto, a considerar o processo de "disembedding" do meio ambiente do seu contexto geográfico, já que este pode ser inserido em fluxos de trocas. Essa abordagem expressa, para os otimistas, o surgimento de um capitalismo mais reflexivo em relação à sua dependência da natureza, como um sinal positivo de um manifesto anseio por reformas por parte de agentes racionais confrontados com os limites do sistema econômico (teorias da modernização ecológica). Podemos ainda, com olhar mais pessimista, interpretá-la de forma mais cínica, como a manifestação de um sistema que leva ao extremo a sua lógica predadora e se sabota, esgotando seus últimos recursos para alimentar uma nova frente de negócios.

No campo político e filosófico, a mobilização dessa abordagem traduz um ponto de vista crítico do observador sobre os processos em curso e uma vontade de voltar a politizar a questão ambiental. Para muitos científicos e ativistas, a ideia de um mercado ambiental que neutralizaria os conflitos socioambientais entorno da definição do justo preço, elimina reflexões e decisões fundamentais sobre a responsabilidade, a força coercitiva da regulação e a necessidade de se fazer escolhas coletivas a favor de determinadas opções e em detrimento de outras. Cada uma das opções coletivas prejudica ou até exclui certos agentes ou usos do espaço em nome da conservação, enquanto a regulação pelo mercado delegava essas decisões ao mercado. Sendo assim, a neoliberalização da natureza participa da individualização e despolitização da gestão ambiental, reduzindo os processos biofísicos a um conjunto de "coisas" fetichizadas e extraídas das sociedades na qual se inserem, privilegiando uma visão branda e ageográfica.

Os observadores das experiências falidas de mercantilização da biodiversidade podem interpretá-las como a resiliência do neoliberalismo no próprio coração das experiências ditas pós-neoliberais dos anos 2000 (Bolívia, Equador), que promoveram o fortalecimento da relação utilitarista e mercantil da natureza. Mas o que está por vir é certamente mais provocativo ainda, pois tudo indica que nem o modelo histórico de comando e controle, nem as tentativas de inserir a regulação da natureza no mercado resistirão à onda neoconservadora. Essa está se destacando por ter introduzido com força uma terceira via, mais radical e que parecia superada: aquela do negacionismo ambiental.

\section{AGRADECIMENTOS}

A redação deste artigo se tornou possível graças ao apoio financeiro de instituições públicas brasileiras e francesas. Os autores gostariam de agradecer ao CNRS, que financiou o programa PICS AGROPOWER, bem como à FAPERJ (Fundação Carlos Chagas Filho de Amparo à Pesquisa do Estado do Rio de Janeiro) por ter concedido uma bolsa Jovem Cientista do Nosso Estado a Ève Anne BUHLER

\section{REFERENCIAS}

AUBERTIN, C.; COUVET, D.; FLIPO, F. Une "marchandisation de la nature"? De l'intégration de la nature en économie. Revue du MAUSS Permanente, 9 fevereiro, 2016. $<$ http://www.journaldumauss.net/?Une-

marchandisation-de-la-nature $>$. Acessed: August, 20, 2019.

AUBERTIN, C.; DENIS, C.; VEIGA, I. Une interprétation brésilienne des Paiements pour services environnementaux. Souveraineté et développement inclusif. In: SARTRE, X. A.; CASTRO, M.; DUFOUR, S.; OSZWALD, J. (dir.) Political ecology des services écosystémiques. Bruxelas: P. Lang, 2014, p. 163-185. https://doi.org/10.3726/978-3-03526473-9

BAKKER, K. The limits of 'neoliberal natures': Debating green neoliberalism. Progress in Human Geography, 34 (6), p.715-735, 2010. https://doi.org/10.1177/0309132510376849

BAKKER, K. Neoliberal nature, ecological fixes, and the pitfalls of comparative research. Environment and Planning A, 41, p. 17811787, 2009. https://doi.org/10.1068/a4277

BRANNSTROM, C. South America's Neoliberal

Agricultural Frontiers: Places of Environmental Sacrifice or Conservation Opportunity? Ambio, 38 (3), p. 141-149, 2009. https://doi.org/10.1579/0044-7447-38.3.141

BRENNER, N.; PECK, J.; THEODORE, N. Variegated Neoliberalization: Geographies, Modalities, Pathways. Global Networks, 10 (2), p. 182-222, 2010. https://doi.org/10.1111/j.1471-

0374.2009.00277.x

BRENNER, N.; THEODORE, N. Cities and the geographies of 'actually existing neoliberalism’. Antipode, Vol. 34 (3), p. 349379, 2002. https://doi.org/10.1111/14678330.00246

BÜHLER, E. A.; OLIVEIRA, V. L. Néolibéralisation de la nature sur la frontière 
agricole du Cerrado nordestin. Brésil(s), no 13, 2018. https://doi.org/10.4000/bresils.2554

BUTTEL, F. H. Globalization, environmental reform and U.S. hegemony. In: SPAARGAREN, G.; MOL, A.P.J.; BUTTEL, F. $\mathrm{H}$. (editores) Governing environmental flows: global challenges por social theory. Cambridge: Mit Press, 2006, p. 157-184.

CASTREE, N. Neoliberalising nature: the logics of deregulation and reregulation. Environment and Planning A, 40, p.131152, 2008. https://doi.org/10.1068/a3999

CASTREE, N. Comodifying what nature? Progress in Human Geography, 27 (3), p. 273-297, 2003. https://doi.org/10.1191/0309132503ph428oa

COSTANZA, R.; D'ARGE, R.; DE GROOT, R.; FARBER, S.; GRASSO, M.; HANNON, B.; LIMBURG, K.; NAEEM, S.; O'NEILL, R.V.; PARUELO, J.; RASKIN, G.R.; SUTTON, P.; VAN DER BELT, M. The value of the world's ecosystem services and natural capital. Nature, 387, p. 253-260, 1997. https://doi.org/10.1038/387253a0

DARDOT, P. Le capitalisme à la lumière du néolibéralisme. Raisons politiques, 52 (4), p. 13-23,

2013.

https://doi.org/10.3917/rai.052.0013

DUMOULIN-KERVRAN, D. Les ONG latinoaméricaines après l'âge d'or: internationalisation et dispersion. In: ZAGEFKA, P. (dir.) Amérique latine 2006, Paris: La Documentation Française, p. 31-50, 2006. <http://hal.archives-ouvertes.fr/halshs00163758/>. Acessado: 20 de agosto de 2019.

DUMOULIN KERVRAN, D.; RODARY, E. Les ONG, au centre du secteur mondial de la conservation de la biodiversité. In: AUBERTIN, C. (ed.) Représenter la nature? ONG et biodiversité. Paris: IRD Editions, 2005, p. 59-97. https://doi.org/10.4000/books.irdeditions.5642

EKERS, M.; SCOTT P. Towards the SocioEcological Fix. Environment and Planning A: Economy and Space, 47 (12), p. 2438-2445, 2015.

https://doi.org/10.1177/0308518X15617573

ELOY, L.; COUDEL, E.; TONI, F. Implementando Pagamentos por Serviços Ambientais no Brasil: caminhos para uma reflexão crítica. Sustentabilidade em Debate, 4(1), 21-42, 2013. https://doi.org/10.18472/SustDeb.v4n1.2013.9 198

FOYER, J.; VIARD-CRÉTAT, A.; BOISVERT, V. Néoliberaliser sans marchandiser? La bioprospection et les mécanismes REDD dans l'économie de la promesse. In: COMPAGNON, D.; RODARY, E. (org.) Les politiques de biodiversité. Paris: Presses de Science Po, 2017, p. 225-249.

FREITAS, C.; MARSTON, A. J.; BAKKER, K. Not-quite-neoliberal natures in Latin America: An introduction. Geoforum, 64, p. 239-245, 2015.

https://doi.org/10.1016/j.geoforum.2015.05.021 GAUTREAU, P.; GISCLARD, M.; LANGBEHN, L.; MARQUIS DUPONT, G. Regular as fronteiras agrícolas sul-americanas? Experiências e negociações ambientais no Chaco argentino, no Uruguai e no Rio Grande do Sul-Brasil. In: BÜHLER, E. A.; GUIBERT, M.; OLIVEIRA, V. L. Agriculturas empresariais e espaços rurais na globalização. Porto Alegre - RS: UFRGS Editora, 2016, p.171-190. https://doi.org/10.7476/9786557250044.0009

GAUTREAU, P.; MONEBHURRUN, N. Direito à informação ambiental. Uma agenda de pesquisa interdisciplinária. Brasília: Prisma, 2017.

GODARD, O.; HOMMEL, T. Les multinationales et le développement durable: un jeu ambigu. Chaire développement durable, Cahier 2005-021, Paris: EdF- École polytechnique, p.101-112, 2005. https://doi.org/10.3917/ris.060.0101

GROS, C.; DUMOULIN KERVRAN, D.; LEE, D. J. (org.) Le multiculturalisme " au concret ": un modèle latino-américain. Paris: Presses Sorbonne nouvelle, 2011.

HARVEY, D. O neoliberalismo. História e implicações. São Paulo: Loyola, 2011.

MARIS, V. Nature à vendre. Paris: Editions Quæ, 2014.

MARTÍNEZ-ALIER, J. El Ecologismo de los pobres: conflictos ambientales y lenguajes de valoración. Barcelona: FLACSO Ecología ICARIA Antrazit, 2004.

MARTINEZ-ALIER, J., MUNDA, G., O'NEILL, J. Weak comparability of values as a foundation for ecological economics. Ecological Economics, 26 (3). P. 277-286, $1998 . \quad$ https://doi.org/10.1016/S09218009(97)00120-1

MCAFEE, K.; SHAPIRO, E. N. Payments for Ecosystem Services in Mexico: Nature, Neoliberalism, Social Movements, and the State. Annals of the Association of American Geographers, 100 (3), p. 579-99, 2010.

https://doi.org/10.1080/00045601003794833

MORANGE, M.; FOL, S. City, Neoliberalisation and justice. Justice Spatiale | Spatial Justice, $6, \quad$ julho 2014. $<$ https://www.jssj.org/wpcontent/uploads/2014/05/Intro-Eng-numero-6jssj2.pdf>. Acessado: 15 de janeiro de 2019. 
OLIVEIRA, V.; BÜHLER, E. A. Técnica e natureza no desenvolvimento do agronegócio. Caderno CRH (Online), v. 29, p. 261-280, 2016. https://doi.org/10.1590/S010349792016000200005

PECK, J.; BRENNER, N.; THEODORE N. Actually existing neoliberalism. In: CAHILL, D.; COOPER, M.; KONINGS M.; PRIMROSE, D. The Sage handbook of neoliberalism. Londres: SAGE, 2018, p. 3-15. http://dx.doi.org/10.4135/9781526416001

RODARY, E. La conservation intégrée en Afrique australe: opportunité ou contrainte au développement? In: RODARY, E.; CASTELLANET, C.; ROSSI, G. Conservation de la nature et développement. L'intégration impossible? Paris: GRET-Karthala, 2003, p.121-141.

ROSA, T. F. L'agrobusiness brésilien en quête de durabilité. Une évaluation du Plan ABC. Mestrado em geografia " Géographie des pays émergents et en développement ». Paris: Université Paris 1 Panthéon-Sorbonne, 2017.

SCOTT, J. C. Seeing like a State: How Certain Schemes to Improve the Human Condition Have Failed. New Haven: Yale University Press, 1998.

SNA - Sociedade Nacional de Agricultura. Agricultura precisa conciliar produção com proteção, diz ministra Isabella Teixeira. 2015. <http://www.sna.agr.br/agricultura-precisaconciliar-producao-com-protecao-diz-ministraisabella-teixeira/>. Acessado: 15 de fevereiro de 2019.

SWYNGEDOUW, E. CO2 as neoliberal fetish: the love of crisis and the depoliticized immunobiopolitics of climate change governance. In: CAHILL, D.; COOPER, M.; KONINGS M.; PRIMROSE, D. The Sage handbook of neoliberalism. Londres: SAGE, 2018, p. 295307. http://dx.doi.org/10.4135/9781526416001 TONNEAU, J-P.; GUENEAU, S.; PIKETTY, M.G.; DRIGO, I.; POCCARD-CHAPUIS, R. Agro-industrial Strategies and Voluntary Mechanisms for the Sustainability of Tropical Global Value Chains: The Place of Territories. In: BIENABE, E.; RIVAL, A.; LOEILLET, D. Sustainable Development and Tropical Agri-chains. Versailles: Quae, 2017, p. 271282. https://doi.org/10.1007/978-94-024-1016$7 \_22$ 